\title{
Pre- and Post-Transplant Antiviral Therapy (HBV, HCV)
}

\author{
Martin-Walter Welker Stefan Zeuzem \\ Medizinische Klinik 1, Universitätsklinikum Frankfurt, Frankfurt am Main, Germany
}

Keywords

Hepatitis B virus · HBV - Hepatitis C virus . HCV .

Liver transplantation - LTX

\section{Summary}

Background: Hepatitis B virus (HBV)- and hepatitis C virus (HCV)-associated liver cirrhosis is a major indication for liver transplantation. This concise review gives an overview about current interferon (IFN)-free treatment options before and after liver transplantation in HBV- or HCV-associated liver disease. Methods: A PubMed database search using the terms hepatitis $B$, hepatitis $C$, cirrhosis, and liver transplantation was performed to identify significant clinical studies as well as national and international guidelines. Results: Studies investigating IFN-free treatment in patients with decompensated $\mathrm{HBV}$ as well as in HCV-associated cirrhosis are scarce. Hepatic recompensation during antiviral therapy seems more frequent in patients with HBV than in those with $\mathrm{HCV}$-associated cirrhosis. Graft hepatitis B or C is characterized by an accelerated and unfavorable course. Graft infection prophylaxis is safe and efficacious in HBV-related liver transplantation. Eradication of $\mathrm{HCV}$ prior to liver transplantation prevents HCV graft infection, and IFN-free treatment of established HCV graft infection is safe and associated with high sustained virologic response rates. Conclusion: Patients with HBV-associated cirrhosis should be treated prior to liver transplantation, and receive a continuing graft infection prophylaxis thereafter. Patients with HCV-associated decompensated cirrhosis may be considered as candidates for antiviral therapy prior to liver transplantation or may be treated subsequently.

(c) 2016 S. Karger GmbH, Freiburg

\section{Introduction}

The worldwide prevalence of hepatitis B virus (HBV) and hepatitis $\mathrm{C}$ virus ( $\mathrm{HCV}$ ) infection is estimated to $350-400$ million people and 130-170 million people, respectively [1-5]. Liver failure due to acute or chronic hepatitis $\mathrm{B}$ or $\mathrm{C}$ as well as development of early hepatocellular carcinoma (HCC) in (advanced) HBV- or HCV-related liver disease are important indications for liver transplantation in the Eurotransplant (ET) and United Network for Organ Sharing (UNOS) regions as well as in Northeast Asia [6-8].

Goals for antiviral therapy before and after liver transplantation can be (i) improvement of liver function to avoid liver transplantation, (ii) stabilization of liver function to reduce waitlist mortality, (iii) risk reduction of virus graft infection, and (iv) treatment of established graft infection after liver transplantation [9-12]. The use of (pegylated (PEG)) interferon (IFN)-alfa is generally not recommended in patients with hepatitis $\mathrm{B}(/ \mathrm{D})$ - or hepatitis C-associated decompensated cirrhosis because of the risk of hepatic decompensation. After liver transplantation, IFN-alfa-associated plasma cell hepatitis is a major concern [9-12]. Therefore, this article is limited to IFN-free treatment options in these patient cohorts.

\section{Antiviral Therapy in HBV-Associated Liver Cirrhosis and Liver Transplantation}

Liver failure due to fulminant or chronic hepatitis B or B/D accounts for approximately $5 \%$ of liver transplantations in the ET and UNOS regions $[13,14]$. In the era before the introduction of effective (immune-)prophylaxis for HBV graft infection and treatment with nucleos(t)ide analogues of patients with established HBV graft infection, the prognosis of HBV-related liver transplantation was poor due to an accelerated course of HBV graft infection including fulminant hepatitis and fibrosing cholestatic hepatitis [15]. Today, liver transplantation due to chronic hepatitis B can often be prevented and prognosis after liver transplantation is markedly improved $[9,10,15,16]$.

\section{KARGER \\ Fax +497614520714

PD Dr. med. Martin-Walter Welker 


\section{Treatment of Patients with HBV-Associated Liver Cirrhosis Pre-Transplant}

Antiviral treatment of patients with HBV-related cirrhosis is associated with risk reduction of hepatic decompensation and HCC development $[17,18]$. Furthermore, enduring suppression of viral replication is associated with improved survival in patients with HBV-associated cirrhosis [19]. Therefore, antiviral treatment with a nucleos $(\mathrm{t})$ ide analogue is recommended in all patients with HBVassociated cirrhosis and detectable HBV DNA [9, 10]. Hepatic function may improve even in patients with decompensated HBVrelated cirrhosis, and in patients listed for liver transplantation improvement of liver function may allow avoiding liver transplantation in the end [10]. The nucleos(t)ide analogues lamivudine, entecavir, telbivudine, adefovir, and tenofovir have been approved by the European Medicines Agency (EMA) and the Food and Drug Administration (FDA) for the treatment of chronic hepatitis B. Inter alia, these agents differ with respect to antiviral efficacy and barrier to resistance [10]. This is of special importance in the setting of (decompensated) cirrhosis, as development of drug resistance may be associated with clinical complications and increased mortality in these patients $[18,19]$. Despite an overall favorable safety profile, concerns remain that development of lactic acidosis in patients with decompensated cirrhosis may be a class effect of nucleos(t)ide analogues [10]. Current data indicate that entecavir and tenofovir have a good safety profile even in patients with decompensated cirrhosis [20-22]. However, an adequate number of patients with decompensated cirrhosis and a model of end stage liver disease (MELD) score $\geq 22$ was not included in the respective trials; thus, all nucleos(t)ide analogues including entecavir and tenofovir should be administered with caution to patients with decompensated cirrhosis and a MELD score $\geq 22$ [10, 20-22]. Furthermore, all nucleos(t)ide analogues must be adjusted to renal function [10]. A considerable advantage of entecavir and tenofovir among the nucleos $(\mathrm{t})$ ide analogues is their high barrier to resistance [23-27]. Moreover, both agents have a high antiviral potency that results in a rapid decline of viral load. This is of advantage in patients who are waiting for a liver transplant since a higher viral load at the time point of transplantation is associated with an increased risk of HBV graft infection [10,15]. The selection of either of the both agents should consider prior antiviral therapies and resistance-associated mutations. Because of partial overlapping resistance, entecavir is not the first choice in patients with lamivudine resistance [10]. Once established, antiviral therapy must not be interrupted or stopped because of the risk of liver failure [10]. Sufficient suppression of viral replication is associated with a reduced risk of HBV graft infection. Thus, all patients with detectable HBV DNA waiting for a liver transplant should be treated with a nucleos $(\mathrm{t})$ ide analogue $[10,15]$. In patients with hepatitis $\mathrm{B} / \mathrm{D}$ related (decompensated) cirrhosis, the treatment options are mostly limited to antiviral treatment of HBV.

\section{Current Strategies for HBV Graft Infection Prophylaxis}

HBV graft infection, defined by detectable hepatitis B surface antigen (HBsAg), occurs in 61-89\% of patients without graft infec-
Table 1. Risk factors for HBV graft infection after liver transplantation (modified from [33])

YMDD mutation / prior treatment with lamivudine ${ }^{\mathrm{a}}$

High replicative hepatitis $\mathrm{B}$ (high viral load, hepatitis B envelope antigen positive) Hepatitis B genotype C infection

ashould not be of importance when e.g. tenofovir is used in HBV graft infection prophylaxis.

tion prophylaxis, depending on pre-transplant viral load and type of liver disease (i.e. acute vs. chronic), whereas patients with fulminant hepatitis $B$ or hepatitis delta virus superinfection have a lower risk of HBV graft infection (table 1) [28, 29]. After the introduction of hepatitis B surface immunoglobulin alone and subsequently in combination with lamivudine as graft infection prophylaxis, the HBV graft infection rate was reduced below 5\% [30]. Combination therapy with hepatitis B surface immunoglobulin and a nucleos $(\mathrm{t})$ ide analogue was found more effective than monotherapy (either immunoglobulin or lamivudine/adefovir) [31]. Although several studies have been performed to identify patients in whom HBV graft infection prophylaxis may be completely stopped or reduced, indefinite continuation of combined prophylaxis with immunoglobulin and a nucleos $(\mathrm{t})$ ide analogue remains recommended [10, 32,33 . Hepatitis B immunoglobulin can be administered subcutaneously, intramuscularly, or intravenously. The application interval should be adjusted to ensure an anti-hepatitis B surface antibody titre $>100 \mathrm{mIE} / \mathrm{ml}[10]$. The combination nucleos(t)ide analogue partner for HBV graft infection prophylaxis should be chosen with respect to putative resistance-associated mutations and antiviral therapy prior to transplantation. In the long term, however, an indefinite mono-prophylaxis with a potent nucleos(t)ide analogue with a high barrier to resistance (e.g. entecavir, tenofovir) may be considered [10,34]. Finally, active immunization against HBsAg may be an option in selected patients $[10,35]$.

\section{Treatment of Established HBV Graft Infection}

If HBsAg stays detectable longer than 14 days after transplantation or becomes detectable after transient absence, HBV graft infection prophylaxis has failed. Unlimited antiviral therapy with a nucleos(t)ide analogue should be initiated immediately. Significant drug-drug interactions with immunosuppressive agents have not been reported, but again, dosing must be adjusted to renal function $[9,10]$.

\section{Antiviral Therapy in HCV-Associated Liver Cirrhosis and HCV Liver Graft Infection}

Chronic hepatitis C-associated liver disease accounts for 13$25 \%$ of liver transplantations in the ET and UNOS regions $[13,36]$. The leading indications for liver transplantation are functional liver failure and early HCC in patients with compensated cirrhosis [37]. This article focuses on the antiviral treatment of patients with decompensated cirrhosis. 
Table 2. Efficacy of (PEG-)IFN-free antiviral therapy in patients with HCVassociated decompensated cirrhosis in controlled, prospective trials

\begin{tabular}{llllllll}
\hline Author & Therapy regime & $\begin{array}{l}\text { Treatment } \\
\text { duration, } \\
\text { weeks }\end{array}$ & Genotype $^{\mathrm{a}}$ & $\mathrm{n}$ (all) & $\begin{array}{l}\mathrm{n} \text { (MELD } \\
>16)\end{array}$ & SVR $_{12}$ (all), n & $\begin{array}{l}\text { SVR }_{12} \\
\text { (MELD }> \\
16), \mathrm{n}\end{array}$ \\
\hline Charlton M, et al. [39] $^{\text {b }}$ & LDV/SOF + RBV & $12-24$ & 1,4 & $108^{\mathrm{d}}$ & 27 & $89 / 108(82 \%)$ & $\mathrm{ns}$ \\
Curry MP, et al. [40] & SOF/VEL \pm RBV & $12-24$ & $1,2,3,4,6$ & 267 & 12 & $234 / 267(88 \%)$ & $\mathrm{ns}$ \\
Manns M, et al. [43] $^{\mathrm{b}}$ & LDV/SOF/RBV & 12 & 1,4 & 140 & 41 & $121 / 140(86 \%)$ & $\mathrm{ns}$ \\
Poordad F, et al. [42] & LDV/SOF + RBV & $12(-24)$ & $1,2,3,4,6$ & $60^{\mathrm{d}}$ & 13 & $50 / 60(83 \%)$ & $\mathrm{ns}$ \\
\hline
\end{tabular}

${ }^{\mathrm{a}}$ Most studies investigated mainly genotype 1 .

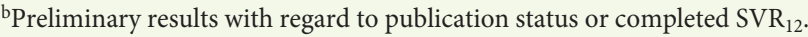

'Until November 2015, VEL has not been not approved by the EMA or FDA yet.

${ }^{\mathrm{d}}$ The complete study included patients prior to and after liver transplantation.

$\mathrm{DCV}=$ Daclatasvir; $\mathrm{LDV}=$ ledipasvir; $\mathrm{RBV}=$ ribavirin; $\mathrm{SMV}=$ simeprevir; $\mathrm{SOF}=$ sofosbuvir; $\mathrm{VEL}=$ velpatasvir; $\mathrm{ns}=$ not specified.

\section{Treatment of Patients with HCV-Associated Decompensated Cirrhosis Pre-Transplant}

Prospective, randomized studies investigating (PEG-)IFN-free treatment which enrolled a significant number of patients with decompensated cirrhosis (Child-Pugh (CP) score > 8; MELD score > 16) are scarce, and safety as well as efficacy data are only available in individual cases for patients with a MELD score $>22$ (table 2) [38-45]. In the ALLY-1 study, which enrolled patients with advanced cirrhosis and patients after liver transplantation, sustained virologic response (SVR) was achieved in 11/12 (92\%), 30/32 (94\%), and 9/16 (56\%) patients with CP class A, B, and C cirrhosis, respectively [42]. The chance of achieving SVR seems therefore inversely correlated with liver function in patients with advanced cirrhosis prior to liver transplantation, although data are inconsistent in different studies [38-43]. Reliable predictive markers to estimate SVR or the clinical course during and after IFN-free therapy have not yet been identified in patients with decompensated HCV-associated cirrhosis. Moreover, SVR does not mean cure from cirrhosis. Published studies show that an improvement in CP or MELD score was only observed in a proportion of patients, while liver function remained unchanged or even worsened in a significant number of patients despite SVR [39-43].

The limited data in patients with decompensated cirrhosis precludes detailed recommendations for the treatment of different genotypes, the treatment duration (12 vs. 24 weeks), or the importance of ribavirin (RBV). Nevertheless, safety issues narrow treatment options. Up to November 2015, daclatasvir (DCV), dasabuvir (DSV), ledipasvir (LDV)/sofosbuvir (SOF), simeprevir (SMV), $\mathrm{SOF}$, ombitasvir (OMV), and paritaprevir/ritonavir (PTV/r) have been approved by the EMA and the FDA in different combinations with or without RBV as partners in (PEG-)IFN-free antiviral therapy regimens, but only DCV/SOF, LDV/SOF, and SOF with or without RBV have been approved for patients with decompensated cirrhosis. The combination of SOF with RBV instead of LDV/SOF with RBV is generally not recommended due to lower efficacy [11]. (Interim) analyses of the prospective phase III study ALLY-1 and compassionate use programs indicate that the use of DCV is safe in patients with advanced cirrhosis $[42,44,45]$. In contrast, the safety of SMV in patients with decompensated cirrhosis has not been conclusively evaluated [46-51]. Recently, a safety warning by the
FDA resulted in a contraindication for DSV in combination with $\mathrm{OMV}$ and $\mathrm{PTV} / \mathrm{r}$ in patients with liver cirrhosis $\mathrm{CP} \geq \mathrm{B}$ [52]. Therefore, only SOF plus RBV, and DCV/SOF as well as LDV/SOF alone or in combination with RBV are approved treatment options in patients with decompensated cirrhosis, while comprehensive safety data of SMV in patients with decompensated cirrhosis are still pending [38-41].

It seems reasonable that the decision whether antiviral therapy in patients with decompensated cirrhosis with a moderate (16-22) or high ( $\geq 22)$ MELD score may be initiated prior to or after liver transplantation should be based on the distinct clinical situation and the availability and waiting time for organs. Of note, SVR is associated with an improvement of portal hypertension [53-56], and even delisting from the liver transplant waitlist may be possible in some cases $[57,58]$.

Individual reasons favoring antiviral therapy prior to liver transplantation may be the stabilization of liver function to reduce waiting time mortality or enable antitumor therapy in patients with concomitant early HCC, and lastly the prevention of HCV graft infection [59]. Reasons against antiviral therapy prior to transplantation may be the improvement of laboratory values and consecutively improvement in MELD score despite continued clinical need for transplantation, and the reduced efficacy of antiviral therapy in patients with decompensated cirrhosis with the putative risk of selection of resistance-associated variants.

\section{Treatment of Established HCV Graft Infection}

Graft infection is nearly unavoidable in patients with detectable HCV RNA at transplantation. The natural course of hepatitis C after liver transplantation is often severe with a high risk of progression to graft cirrhosis within a few years [60]. Although (PEG-) IFN-based antiviral therapy is associated with enhanced survival in patients with HCV liver graft infection, overall SVR rates are disappointing and severe adverse events are common [61-64].

Meanwhile, controlled, prospective studies investigating (PEG-) IFN-free treatment in patients with HCV graft infection have been published, showing consistently good tolerability and high SVR rates (table 3) [42, 43, 65-69]. In an open multicenter study of HCV graft infection in a real-world setting, SVR 12 weeks after the end of treatment was achieved in 133/151 (88\%) patients receiving a SMV/ 
Table 3. Efficacy of (PEG-)IFN-free antiviral therapy in patients with $\mathrm{HCV}$ liver graft infection in controlled, prospective trials

\begin{tabular}{|c|c|c|c|c|c|}
\hline Author & Therapy regime & $\begin{array}{l}\text { Treatment } \\
\text { duration, } \\
\text { weeks }\end{array}$ & Genotype $^{\mathrm{a}}$ & $\mathrm{n}$ & $\mathrm{SVR}_{12, \mathrm{n}}$ \\
\hline Charlton M, et al. [39] & $\mathrm{LDV} / \mathrm{RBV}+\mathrm{RBV}$ & $12-24$ & 1,4 & $229^{b}$ & $214 / 229(93 \%)$ \\
\hline Charlton M, et al. [68] & $\mathrm{SOF}+\mathrm{RBV}$ & 24 & $1,3,4$ & 40 & $28 / 40(70 \%)$ \\
\hline Kwo PY, et al. [67] & $\mathrm{DSV}+\mathrm{OMV} / \mathrm{PTV} / \mathrm{r}+\mathrm{RBV}$ & 24 & 1 & 34 & $33 / 34(97 \%)$ \\
\hline Manns M, et al. [43] ${ }^{\mathrm{c}}$ & $\mathrm{LDV} / \mathrm{SOF}+\mathrm{RBV}$ & 12 or 24 & 1,4 & $168^{c}$ & $146 / 151(97 \%)^{c}$ \\
\hline Poordad F, et al. [42] ${ }^{c}$ & $\mathrm{DCV} / \mathrm{SOF}+\mathrm{RBV}$ & 12 & $1,2,3,4,6$ & $53^{\mathrm{b}}$ & $50 / 53(94 \%)$ \\
\hline Pungpapong S, et al. [69] ${ }^{\mathrm{C}}$ & $S M V+S O F \pm R B V$ & 12 & 1 & $123^{c}$ & $94 / 105(90 \%)^{c}$ \\
\hline
\end{tabular}

${ }^{a}$ Most studies investigated mainly genotype 1 .

${ }^{b}$ The complete study included patients prior to and after liver transplantation. 9 of 229 patients summarized here had graft cirrhosis and a MELD score $>15$.

cPreliminary results with regard to publication status or completed $\mathrm{SVR}_{12}$ (SVR not available in all patients enrolled into the study). $\mathrm{DCV}=$ Daclatasvir; LDV = ledipasvir; RBV = ribavirin; $\mathrm{SMV}=$ simeprevir; $\mathrm{SOF}=$ sofosbuvir.
SOF-based antiviral therapy regime with and without RBV [70]. With respect to the good tolerability and high SVR rates, all patients with HCV graft infection should be offered a (PEG-)IFN-free treatment regimen [11, 42, 43, 65-69]. Specific contraindications of given treatment regimens (e.g. profoundly impaired renal function, comedication) must be paid regard to. Drug-drug interactions of direct-acting antiviral agents and immunosuppressive agents must be considered [67]. In patients with (decompensated) HCV graft cirrhosis, antiviral treatment may be the sole chance to improve patient and graft survival, and should be strongly considered despite the lack of profound data. In all patients with graft cirrhosis, HCC surveillance remains mandatory after HCV eradication.

\section{Conclusion}

Patients with HBV-associated cirrhosis should be treated with a nucleos $(\mathrm{t})$ ide analogue prior to liver transplantation, and receive a continuing graft infection prophylaxis after transplantation. Patients with $\mathrm{HCV}$-associated cirrhosis and a MELD score $<16$ may be considered candidates for a (PEG-)IFN-free antiviral treatment regimen. In patients with a MELD score $\geq 16$ and especially $\geq 22$, the decision whether antiviral therapy should be initiated before or after transplantation must be based on individual severity of liver disease, the indication for liver transplantation, comorbidities, the chance of SVR with respect to genotype and potential prior antiviral therapies, and the presumed remaining waiting time for graft allocation. Patients with established HCV graft infection should be offered (PEG-)IFN-free antiviral treatment.

\section{Disclosure Statement}

Martin-Walter Welker: Consultancies for AbbVie, Amgen, Novartis, and Roche. Travel support: Astellas, Bayer, Novartis, Janssen, and Roche.

Stefan Zeuzem: Consultancies/speaker's bureau for Abbvie, BMS, Gilead, Janssen, and Merck.

\section{References}

1 Dienstag JL: Hepatitis B virus infection. N Engl J Med 2008;359:1486-1500.

2 World Health Organization: Hepatitis B. 2015. www. who.int/mediacentre/factsheets/fs204/en/.

3 Schweitzer A, Horn J, Mikolajczyk RT, Krause G, Ott JJ: Estimations of worldwide prevalence of chronic hepatitis B virus infection: a systematic review of data published between 1965 and 2013. Lancet 2015;386: 1546-1555.

4 Lavanchy D: The global burden of hepatitis C. Liver Int 2009;29(suppl 1):74-81.

$\checkmark 5$ Hope VD, Eramova I, Capurro D, Donoghoe MC Prevalence and estimation of hepatitis B and C infections in the WHO European Region: a review of data focusing on the countries outside the European Union and the European Free Trade Association. Epidemiol Infect 2013;142:270-286

6 Shukla A, Vadeyar H, Rela M, Shah S: Liver transplantation: East versus West. J Clin Exp Hepatol 2013;3: 243-253.
7 Schoening WN, Buescher N, Rademacher S, et al: Twenty-year longitudinal follow-up after orthotopic liver transplantation: a single-center experience of 313 consecutive cases. Am J Transpl 2013;13:2384-2394.

8 Roberts MS, Angus DC, Bryce CL, Valenta Z, Weissfeld L: Survival after liver transplantation in the United States: a disease-specific analysis of the UNOS database. Liver Transpl 2004;10:886-897.

- European Association for the Study of the Liver: EASL clinical practice guidelines: management of chronic hepatitis B virus infection. J Hepatol 2012;57:167-185.

10 Cornberg M, Protzer U, Petersen J, et al: Prophylaxis, diagnosis and therapy of hepatitis $\mathrm{B}$ virus infection the German guideline (article in German). Z Gastroenterol 2011;49:871-930.

11 Sarrazin C, Berg T, Buggisch P, et al: S3 guideline hepatitis $\mathrm{C}$ addendum (article in German). Z Gastroenterol 2015;53:320-334.

12 European Association for the Study of the Liver: EASL recommendations on treatment of hepatitis C 2015. J Hepatol 2015;63:199-236.
3 Adam R, Karam V, Delvart V, et al: Evolution of indications and results of liver transplantation in Europe. A report from the European Liver Transplant Registry (ELTR). J Hepatol 2012;57:675-688.

14 Camci C, Gurakar A, Rose J, et al: Liver transplantation for hepatitis B in the United States. Transplant Proc 2005;37:4350-4353.

15 Shouval D, Samuel D: Hepatitis B immune globulin to prevent hepatitis B virus graft reinfection following liver transplantation: a concise review. Hepatology 2000; 32:1189-1195.

16 Waki K, Sugawara Y, Tamura S, et al: Outcome of liver transplantation for recipients with hepatitis B and hepatitis $\mathrm{C}$ virus coinfection: analysis of the UNOS data. Transplantation 2011;92:809-814.

17 Papatheodoridis GV, Lampertico P, Manolakopoulos $\mathrm{S}$, Lok A: Incidence of hepatocellular carcinoma in chronic hepatitis B patients receiving nucleos(t)ide therapy: a systematic review. J Hepatol 2010;53:348356. 
18 Liaw Y-F, Sung JJY, Chow WC, et al: Lamivudine for patients with chronic hepatitis B and advanced liver disease. N Engl J Med 2004;351:1521-1531.

19 Di Marco V, Marzano A, Lampertico P, et al: Clinical outcome of HBeAg-negative chronic hepatitis B in relation to virological response to lamivudine. Hepatology 2004;40:883-891.

20 Zhang X, Liu L, Zhang M, et al: The efficacy and safety of entecavir in patients with chronic hepatitis B-associated liver failure: a meta-analysis. Ann Hepatol 2015; 14:150-160.

21 Keating GM, Santoro A: Sorafenib: a review of its use in advanced hepatocellular carcinoma. Drugs 2009;69: 223-240.

22 Miquel M, Núñez Ó, Trapero-Marugán M, et al: Efficacy and safety of entecavir and/or tenofovir in hepatitis B compensated and decompensated cirrhotic patients in clinical practice. Ann Hepatol 2013;12:205212.

23 Liaw Y-F, Sheen I-S, Lee C-M, et al: Tenofovir disoproxil fumarate (TDF), emtricitabine/TDF, and entecavir in patients with decompensated chronic hepatitis B liver disease. Hepatology 2011;53:62-72.

24 Shim JH, Lee HC, Kim KM, et al: Efficacy of entecavir in treatment-naïve patients with hepatitis B virus-related decompensated cirrhosis. J Hepatol 2010;52:176182.

25 Villeneuve JP, Condreay LD, Willems B, et al: Lamivudine treatment for decompensated cirrhosis resulting from chronic hepatitis B. Hepatology 2000;31:207-210.

26 Chan HLY, Chen YC, Gane EJ, et al: Randomized clinical trial: efficacy and safety of telbivudine and lamivudine in treatment-naïve patients with HBV-related decompensated cirrhosis. J Viral Hepat 2012;19:732-743.

27 Singal AK, Fontana RJ: Meta-analysis: oral anti-viral agents in adults with decompensated hepatitis $B$ virus cirrhosis. Aliment Pharmacol Ther 2012;35:674-689.

28 Lucey MR, Graham DM, Martin P, et al: Recurrence of hepatitis B and delta hepatitis after orthotopic liver transplantation. Gut 1992;33:1390-1396.

29 Samuel D, Muller R, Alexander G, et al: Liver transplantation in European patients with the hepatitis B surface antigen. N Engl J Med 1993;329:1842-1847.

30 Angus PW, McCaughan GW, Gane EJ, Crawford DH, Harley H: Combination low-dose hepatitis B immune globulin and lamivudine therapy provides effective prophylaxis against posttransplantation hepatitis $\mathrm{B}$. Liver Transpl 2000;6:429-433.

31 Katz LH, Paul M, Guy DG, Tur-Kaspa R: Prevention of recurrent hepatitis $B$ virus infection after liver transplantation: hepatitis B immunoglobulin, antiviral drugs, or both? Systematic review and meta-analysis. Transpl Infect Dis 2010;12:292-308.

32 Ishigami M, Ogura Y, Hirooka Y, Goto H: Change of strategies and future perspectives against hepatitis $\mathrm{B}$ virus recurrence after liver transplantation. World J Gastroenterol 2015;21:10290-10298.

33 Harmancı Ö, Selçuk H, Haberal M: Prophylaxis against recurrence in liver transplantation patients with hepatitis B virus: what is new? J Clin Transl Hepatol 2014;2: 259-265.

34 Xi Z-F, Xia Q: Recent advances in prevention of hepatitis B recurrence after liver transplantation. World J Gastroenterol 2015;21:829-835.

35 Yoshizawa A, Yamashiki N, Ueda Y, et al: Long-term efficacy of hepatitis $\mathrm{B}$ vaccination as post-transplant prophylaxis in hepatitis B surface antigen (HBsAg) positive recipients and $\mathrm{HBsAg}$ negative recipients of anti-hepatitis B core positive grafts. Hepatol Res 2015; DOI: $10.1111 /$ hepr.12586.

36 Kim WR, Lake JR, Smith JM, et al: OPTN/SRTR 2013 Annual Data Report: liver. Am J Transpl 2015;15 (suppl 2):1-28.
Taniguchi M: Liver transplantation in the MELD era analysis of the OPTN/UNOS registry. Clin Transpl 2012;41-65.

38 Ferenci P, Kozbial K, Mandorfer M, Hofer H: HCV targeting of patients with cirrhosis. J Hepatol 2015;63: 1015-1022.

39 Charlton M, Everson GT, Flamm SL, et al: Ledipasvir and sofosbuvir plus ribavirin for treatment of HCV infection in patients with advanced liver disease. Gastroenterology 2015;149:649-659.

40 Curry MP, O’Leary JG, Bzowej N, et al: Sofosbuvir and velpatasvir for HCV in patients with decompensated cirrhosis. N Engl J Med 2015;373:2618-2628.

41 Afdhal N, Everson G, Calleja JL, et al: Sofosbuvir and ribavirin for the treatment of chronic HCV with cirrhosis and portal hypertension with and without decompensation: early virologic response and safety. J Hepatol 2014;60:S28.

42 Poordad F, Schiff ER, Vierling JM, et al: Daclatasvir with sofosbuvir and ribavirin for HCV infection with advanced cirrhosis or post-liver transplant recurrence. Hepatology 2016;DOI: 10.1002/hep.28446.

43 Manns M, Samuel D, Gane EJ, et al.; SOLAR-2 Investigators: Ledipasvir and sofosbuvir plus ribavirin in patients with genotype 1 or 4 hepatitis $\mathrm{C}$ virus infection and advanced liver disease: a multicenter open-label, randomized, phase 2 trial. Lancet Infect Dis 2016;DOI: 10.1016/S1473-3099(16)00052-9.

44 Welzel T, Petersen J, Gschwantler M, et al: Daclatasvir plus sofosbuvir with or without ribavirin in patients infected with HCV genotype 3: interim results of a multicenter compassionate use program in Europe. Z Gastroenterol 2015;53:KG150.

45 Hezode C, de Ledinghen V, Fontaine H, et al: Daclatasvir plus sofosbuvir with or without ribavirin in genotype 3 patients from a large French multicenter compassionate use program. J Hepatol 2015;62(suppl 2): S265-266.

46 Shiffman ML, James AM, Long AG, Alexander PC: Treatment of chronic HCV with sofosbuvir and simeprevir in patients with cirrhosis and contraindications to interferon and/or ribavirin. Am J Gastroenterol 2015; 110:1179-1185.

47 Modi AA, Nazario H, Trotter JF, et al: Safety and efficacy of simeprevir plus sofosbuvir with or without ribavirin in patients with decompensated genotype 1 hepatitis C cirrhosis. Liver Transpl 2016;22:281-286.

48 Punzalan CS, Barry C, Zacharias I, et al: Sofosbuvir plus simeprevir treatment of recurrent genotype 1 hepatitis C after liver transplant. Clin Transplant 2015; 29:1105-1111.

49 Lawitz E, Sulkowski MS, Ghalib R, et al: Simeprevir plus sofosbuvir, with or without ribavirin, to treat chronic infection with hepatitis $\mathrm{C}$ virus genotype 1 in non-responders to pegylated interferon and ribavirin and treatment-naive patients: the COSMOS randomised study. Lancet 2014;384:1756-1765.

50 Stine JG, Intagliata N, Shah NL, et al: Hepatic decompensation likely attributable to simeprevir in patients with advanced cirrhosis. Dig Dis Sci 2014;60:10311035.

51 Soriano V, Barreiro P, de Mendoza C, Peña JM: Hepatic decompensation with sofosbuvir plus simeprevir in a patient with Child-Pugh B compensated cirrhosis. Antivir Ther 2016;21:91-92.

52 U.S. Food and Drug Administration: Hepatitis C treatments Viekira Pak and Technivie: drug safety communication - risk of serious liver injury. www.fda.gov/ downloads/Drugs/DrugSafety/UCM468755.pdf.

53 D’Amico G, Garcia-Pagan JC, Luca A, Bosch J: Hepatic vein pressure gradient reduction and prevention of variceal bleeding in cirrhosis: a systematic review. Gastroenterology 2006;131:1611-1624.
54 Iacobellis A, Siciliano M, Perri F, et al: Peginterferon alfa- $2 \mathrm{~b}$ and ribavirin in patients with hepatitis $\mathrm{C}$ virus and decompensated cirrhosis: a controlled study. J Hepatol 2007;46:206-212.

55 Rincon D, Ripoll C, Lo Iacono O, et al: Antiviral therapy decreases hepatic venous pressure gradient in patients with chronic hepatitis $\mathrm{C}$ and advanced fibrosis. Am J Gastroenterol 2006;101:2269-2274.

56 Roberts S, Gordon A, McLean C, et al: Effect of sustained viral response on hepatic venous pressure gradient in hepatitis C-related cirrhosis. Clin Gastroenterol Hepatol 2007;5:932-937.

57 Ruiz I, Feray C, Pawlotsky J-M, Hézode C: Patient with decompensated hepatitis $\mathrm{C}$ virus-related cirrhosis delisted for liver transplantation after successful sofosbuvir-based treatment. Liver Transpl 2015;21:408-409.

58 Coilly A, Pageaux G, Houssel-Debry P, et al: Improving liver function and delisting of patients awaiting liver transplantation for HCV cirrhosis: do we ask too much to DAA? Hepatology 2015;51(suppl):275A.

59 Curry MP, Forns X, Chung RT, et al: Sofosbuvir and ribavirin prevent recurrence of $\mathrm{HCV}$ infection after liver transplantation: an open-label study. Gastroenterology 2015;148:100-107.e1.

60 Gane EJ: The natural history of recurrent hepatitis $C$ and what influences this. Liver Transpl 2008;14(suppl 2): S36-44.

61 Peveling-Oberhag J, Zeuzem S, Hofmann WP: Antiviral therapy of chronic hepatitis $\mathrm{C}$ in patients with advanced liver disease and after liver transplantation. Med Microbiol Immunol 2010;199:1-10.

62 Ikegami T, Yoshizumi T, Shirabe K, Maehara Y: Frequent plasma cell hepatitis during telaprevir-based triple therapy for hepatitis $\mathrm{C}$ after liver transplantation. J Hepatol 2014;60:894-896.

63 Pungpapong S, Aqel BA, Koning L, et al: Multicenter experience using telaprevir or boceprevir with peginterferon and ribavirin to treat hepatitis $\mathrm{C}$ genotype 1 after liver transplantation. Liver Transpl 2013;19:690700.

64 Berenguer M: Systematic review of the treatment of established recurrent hepatitis $C$ with pegylated interferon in combination with ribavirin. J Hepatol 2008; 49:274-287.

65 Reddy KR, Everson GT, Flamm SL, et al: Ledipasvir/ sofosbuvir with ribavirin for the treatment of HCV in patients with post transplant recurrence: preliminary results of a prospective, multicenter study. AASLD 2014, Boston. Hepatology 2014;60(suppl 4):200A.

66 Gutierrez JA, Carrion AF, Avalos D, et al: Sofosbuvir and simeprevir for treatment of hepatitis $\mathrm{C}$ virus infection in liver transplant recipients. Liver Transpl 2015; 21:823-830.

67 Kwo PY, Mantry PS, Coakley E, et al.: An interferonfree antiviral regimen for HCV after liver transplantation. N Engl J Med 2014;371:2375-2382.

68 Charlton M, Gane E, Manns MP, et al: Sofosbuvir and ribavirin for treatment of compensated recurrent hepatitis $C$ virus infection after liver transplantation. Gastroenterology 2014;148:108-117.

69 Pungpapong S, Aqel B, Leise M, et al: Multicenter experience using simeprevir and sofosbuvir with or without ribavirin to treat hepatitis $\mathrm{C}$ genotype 1 after liver transplant. Hepatology 2015;61:1880-1886

70 Brown RS, O’Leary JG, Reddy KR, et al: Interferon-free therapy for genotype 1 hepatitis $\mathrm{C}$ in liver transplant recipients: real world experience from HCV-TARGET. Liver Transpl 2016;22:24-33. 